\title{
The Evolution of IS: Treasury Decision Support \& Management Past, Present \& Future*
}

\author{
Alankar Karol ${ }^{1,}$ Mary-Anne Williams ${ }^{1}$ and Steve Elliot ${ }^{2}$ \\ 1 Innovation and Technology Research Laboratory, University of \\ Technology, Sydney, NSW 2007, Australia \\ \{alankar.karol,mary-anne.williams\}@uts.edu.au \\ 2 School of Business, University of Sydney, NSW, 2006, Australia \\ s.elliot@econ.usyd.edu.au
}

\begin{abstract}
This paper contributes to the discipline of Information Systems (IS) by illustrating the continuing evolution of IS applications to a single, core business function. Historical developments in IS and the major global treasury activity, foreign exchange trading, have been examined to establish the context. Findings from a seven year research project into the impact of ICT on financial services and the development of a next generation agentbased treasury management system prototype have been applied. Possible future developments in IS applications are explored in terms of the capabilities of emerging technologies to address current treasury challenges. The implications for practitioners in an increasingly complex, global market are discussed and sustainable research issues, particularly for IS research, identified.
\end{abstract}

\section{Introduction}

Achieving organisational efficiencies and strategic positioning are key challenges for all firms [1] but those engaging in global markets are confronted by additional challenges, including the necessity for foreign currency exchange. Organizations selling or purchasing internationally outside common currency blocks (e.g., the European Union), require foreign currency exchange as a core business function. These activities are typically undertaken by a corporate treasury department (see section 5 for a description of this function). Developments in Information Systems (IS) over time have presented opportunities for innovation in decision support and management of foreign exchange transactions. Information Systems is a term with

* This research was conducted under the auspices of a Research Project on Business Innovation funded by the Danmarks Nationalbank, the central bank of Denmark and the Australian Research Council.

Please use the following format when citing this chapter:

Karol, A., Williams, M.-A., Elliot, S., 2006, in IFIP International Federation for Information Processing, Volume 214, The Past and Future of Information Systems: 1976-2006 and Beyond, eds. Avison, D., Elliot, S., Krogstie, J., Pries-Heje, J., (Boston: Springer), pp. 89-100. 
many definitions, but the essence of an Information System is that they are applications of Information Technology to meet a challenge or to address a problem.

The research questions are: how has, and can, IS evolve in a core business function? This paper has three aims: to illustrate the continuing evolution of IS through examination of the nature and impact of IS in a single, core business function; to identify sustainable research issues and themes in IS by investigating related IS applications over time; and to assist treasury management (TM) succeed in an increasingly complex, global market by highlighting how next generation IS applications might address its challenges in the future. A multiple method research approach has been adopted with a review of literature, interviews from a seven year research project into the impact of ICT on financial services [2-5] and the "proof of concept' development of a prototype future generation agent-based treasury management system [6].

Related publications from this project have examined, in increasing detail, the technical solutions available or possible to meet current challenges confronting treasury risk management. This paper was prepared specifically to commemorate the $30^{\text {th }}$ anniversary of IFIP TC8: The past, present and future of Information Systems. It takes a reflective, evolutionary analysis of past and present risk management system solutions and then considers the empirical and theoretical implications of likely future developments. The structure is: context is established through an overview of IS roles in management and brief histories of foreign exchange markets and IS; the evolution of treasury management over time is examined; the current status of treasury systems identified; requirements for future treasury management systems determined; the implications for IS research and practice considered and discussed.

\section{The Role of IS in Management}

Five classical functions of management have been identified, (i) Decision Making, (ii) Planning, (iii) Organising, (iv) Coordinating, and (v) Controlling [7].

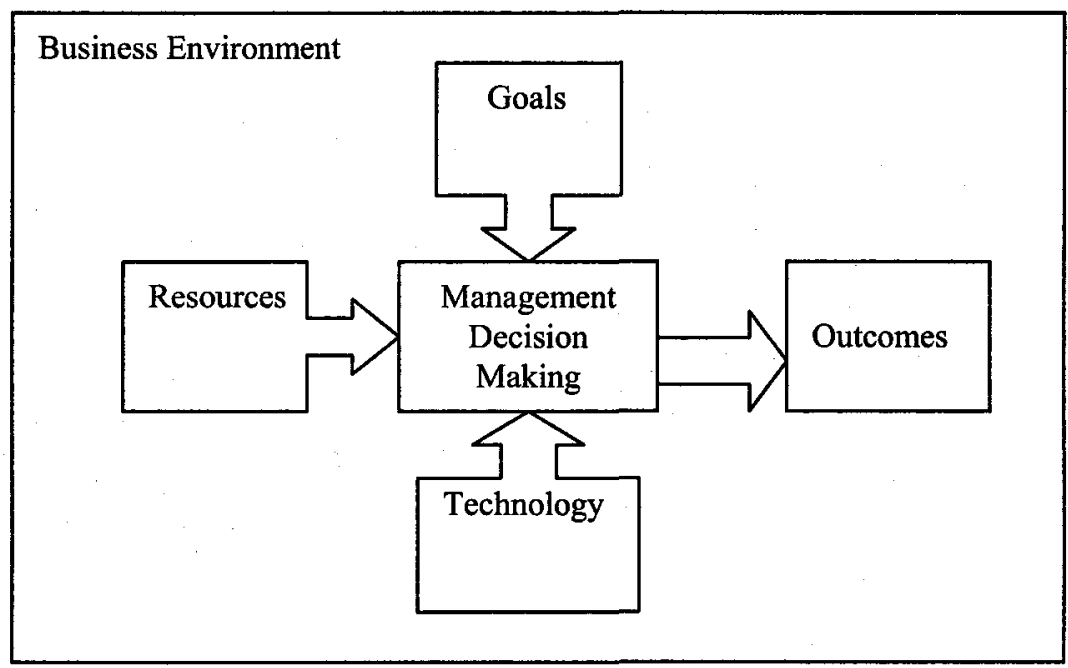

Figure 1: IS supporting decision making in Management. 
The role of IS over time is and has been to provide management with sufficient information to make informed decisions that assist in achieving the five management functions. IS play a crucial role within and across organisations and industries, e.g. they enable, transform, and shape organisational and industry innovations and structures, see Figure 1.

Management can be conceptualised in terms of a goal-directed system of decision processes that take resources such as information, funds, commodities as inputs and produce decision outcomes. Decision making in organisations is typically goal directed, e.g. in pursuit of sustained strategic competitiveness and aboveaverage. Management decision making can be more effective if technology is used appropriately to support management decisions.

Decision making is an essential management activity, and it can be divided into three types: strategic, tactical and operational [4,7]. Operational decision making concerns low level decisions with a short term time horizon, i.e. day to day decision making about operational issues. Tactical decision making is concerned with decisions with a medium term horizon, and strategic decision making focuses on long term high level issues. Strategic management involves deciding on the objectives, resources and policies of the organisation. A major challenge for strategic decision making is anticipating the future opportunities for the organization within a likely environment, to achieve strategic positioning and operational effectiveness.

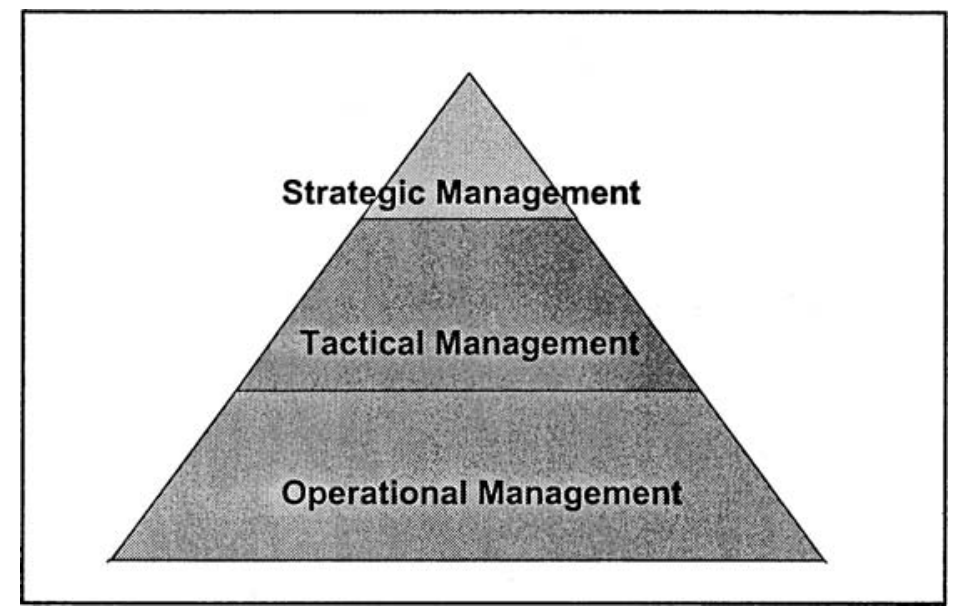

Figure 2: Management hierarchy based on decision making required

Strategic decisions typically have implications for the resource base of the enterprise, i.e. its capital equipment, its work force, its technological base etc, over a medium period of time. Tactical decisions are concerned with efficiency and effectiveness, ensuring resources are properly utilized and the performance of operational units is competitive. Tactical decisions involves close interaction with people performing the tasks of the organisation; ideally it takes place within the context of broad policies and objectives set out by strategic decision making and planning processes. Operational decision making is concerned with specific tasks set forth by strategic and tactical management, including determining which units or 
individuals in the organisation will carry out specified tasks, establishing criteria of completion and resource utilization, and evaluating outcomes. Operational decisions focus on how the enterprise should undertake day-to-day operations in the business environment.

Decisions can also be classified, into three classes: structured, semi-structured and unstructured. Unstructured decisions are typically the highly complex they occur in a context where the problem being addressed is not well understood, e.g. major influence factors may be unknown, uncertain or incomplete. They are often novel, significant, and non-routine, and there is no well-understood procedure for finding the best solution. At the other end of the spectrum structured decisions take place when the decision problem is well understood and all the relevant information is available. They are repetitive, routine, and involve a straightforward procedure [7].

Structured and unstructured decision making and problem solving occurs at all levels of management. In the past, most of the success in most IS came in dealing with structured, operational, and management control decisions. However, gains have been made over time and at present IS has been able to provide significant assistance in the area of semi-structured decision making particularly as technological capabilities have be developed. In the future IS is expected to make some inroads into providing support in assisting decision making in dynamic and complex environments.

According to Simon [8] decision making involves a number of phases: intelligence, design, choice and implementation. The problem or opportunity is identified in the intelligence phase, solutions are proposed in the design phase, and one solution is selected in the choice phase, and implemented in the final phase.

Table 1: Stages in the Treasury decision making process [9]

\begin{tabular}{|c|c|c|}
\hline \multicolumn{2}{|c|}{ Phase of Decision Making } & Treasury Information Requirement \\
\hline 1 & Intelligence & $\begin{array}{l}\text { Business need (e.g. cash flow), business } \\
\text { opportunity, International business contract and } \\
\text { associated risk }\end{array}$ \\
\hline 2 & Design & Modeling, financial information \\
\hline 3 & Choice & $\begin{array}{l}\text { Hypothetical Reasoning, Simulations, Stress } \\
\text { Testing }\end{array}$ \\
\hline 4 & Implementation & Hedge, Option, Swap, FX derivative \\
\hline
\end{tabular}

Table 1 indicates the types of information required for each of the decisionmaking phases. IS need to take into account the needs of managers at each stage of the decision making process since each stage has different requirements.

\section{A Brief History of Foreign Exchange Markets}

A concise review of foreign exchange markets will help to place TM developments into context. Different currencies and the need to exchange them have existed since 
ancient times. The Second World War saw a decline in the trade of foreign exchange, the fall of the British Pound as the major trading currency and the rise of the US Dollar as the new international standard for foreign exchange. In 1944 the Bretton Woods system for exchange rate management made the US dollar as the world's benchmark currency and pegged it to the price of gold at USD 35.00 per ounce. As a consequence all other currencies were pegged to the US dollar and were not allowed to fluctuate more than $1 \%$ on either side of the pegged rate. If any currency did move by more than $1 \%$ then the central bank of that country intervened in the market until the exchange rate returned to the $1 \%$ band. In 1971 The Bretton Wood system was replaced by the Smithsonian system and almost simultaneously the European Community formed the European Joint float in 1972 to break free of the dollar. Both systems collapsed in 1973 resulting in the free floating system. In 1979 the European Monetary System was formed which allowed most of the countries of the European Union to link their currencies to avoid large fluctuations. That system failed in 1993 when the UK withdrew and this led to the formation of the European Central Bank which formally floated the Euro in 1999 as the common currency for most of the nations of the European Union. Today the foreign exchange rates of the different countries are a mix of free floating currencies for the developed nations and currencies of the developing countries pegged to major currencies.

These changes in the foreign exchange markets have most of the major currencies floating freely which has given rise to increased volatility in exchange rates. Some of the most important factors that effect exchange rates are the GDP, the level of business activity, the level of employment, interest rates, inflation rate, trade deficits and even the political climate in either of the two countries involved.

Besides being one of the most volatile markets in the world the foreign exchange market is the largest market in the world with an average daily trading volume of USD 1.9 trillion in April 2004 as compared to USD 650 billion in April 1998 [10]. The foreign exchange market is exceptional due to high liquidity, geographical dispersion, large number and variety of traders and long trading hours.

\section{A Brief History of Information Processing and Systems}

The evolving technological infrastructure helps to place IS developments into a technological context. The history of IS can be divided into four major periods which are characterized by a principal technology used to solve the input, processing, output and communication problems of the time: (i) manual, (ii) mechanical, (iii) electromechanical, and (iv) electronic. The premechanical manual age (3000 B.C. 1450 A.D) was driven by hand writing enabled by paper and pens. The first abacus, developed some time before 300BC (http://en.wikipedia.org/wiki/Abacus).

From an IS perspective the printing press heralded the beginning of the Mechanical Age (1450 - 1840), later slide rules and other algorithmic devices were introduced, and this period culminated in the Babbage machine. The discovery of electricity lead to the Electromechanical Age $(1840$ - 1940) where information could be converted into electrical impulses for transmission via telegraph, telephone and radio. The first computer was built in 1942, and so the so-called Electronic Age extends from then until the present time.

The first generation computing systems (1951 -1958) were based on vacuum tubes as their main logic elements, punch cards to input and externally store data, rotating magnetic drums for internal storage of data and programs which were written in machine language and assembly language. The Second Generation (1959 1963) 
computers were typically based on transistors. Magnetic tape and disks began to supplement punched cards as external storage devices. High-level programming languages like, FORTRAN and COBOL were introduced. The Third Generation (1964-1979) computers used integrated circuits. Operating systems were developed and more advanced languages were developed. The Fourth Generation (1979-1990) is based on large-scale and very large-scale integrated circuits with microprocessors, and CPUs on a single chip. PCs appeared in the 1970s. Fourth generation language software products include Visicalc, Lotus 1-2-3, dBase, Microsoft Word, etc. Computing was transformed by database management systems and personal computers. Fifth generation systems, characterised by higher levels of abstraction in the programming languages, began to emerge in the mid-1980s. Declarative languages like SQL, object-oriented languages like $\mathrm{C}++$ and Java, agent-oriented systems such as BDI, and mark up languages such as html, XML, RDF, OWL emerged. Future technologies will be characterized by agility, biological integration, mobile, pervasiveness and ubiquity $[8,11]$.

\section{Evolution of Treasury Management}

Corporate treasurers are responsible for establishing policies for financial risk management, executing the related practices and then subsequently tracking and reporting the results of the programme. As a result most treasury departments see maintaining adequate access to liquidity, improving working capital utilizations, enhancing cash flow forecasting and monitoring, refining hedge strategies and processes, minimizing transaction costs and rigorous error and compliance checking as their major responsibilities $[9,12]$.

However with the breakdown of the pegged currency systems, globalization of the financial markets, complex derivative instruments on the exchanges and the enhanced volatility of the environment due to threats of global terrorism, the treasury department of most companies find themselves facing new challenges. Expansion into international trade has left more and more companies exposed to foreign exchange exposures and transformed the nature of the key traditional activities of the treasury departments.

The IS capabilities to assist TM have changed with the rapid development in the mathematical models available for the pricing of certain exchange traded instruments like futures and some over the counter instruments like exotic options. The rapid development in mathematical models for the complex derivatives developed in the last two to three decades have shown the limitations of the conventional spread sheet and increased the risk exposure of many companies. The need for non-linear analysis for measuring the risk exposure and hedging strategies has created a need for integrated treasury IS. Important aspects of past, present and future treasury management systems are summarized in Tables 2, 3 and 4 .

Over the last 30 years treasury management systems have moved from entirely manual systems to systems that rely on stand alone PC's with spreadsheet software. Banks have introduced large corporate wide software but still have difficultly managing their systems, e.g. rogue trading.

A survey [10] of 200 leading financial services companies into how they were perceiving and responding to the eBusiness revolution showed concerning mismatches between the reality of eBusiness today and the reaction of the industry to its potential. Many established financial services companies were not responding to 
Table 2: Summary of Treasury Management systems, over time [2,3,9,12]

\begin{tabular}{|c|c|}
\hline \multicolumn{2}{|l|}{ The Past $1976-2005$} \\
\hline Information System Type & Manual, Electromechanical \\
\hline Requirements & Manual advice form \\
\hline Information Gathering & Printed Newspaper for rates and directives from management \\
\hline Level of Management & Mainly operational \\
\hline Transaction Technologies & Telephone, Telefax, Letter Confirmation \\
\hline Transaction Execution & Manual bank transfer \\
\hline Type of Trades & Simple trades, no derivatives \\
\hline Outcome & Gain and losses at the markets will \\
\hline Nature of Risk & No ability to offset risk and exposures \\
\hline Risk Management & Hand held electronic calculators \\
\hline \multicolumn{2}{|l|}{ The Present 2006} \\
\hline Information System Type & Electronic and $4^{\text {th }}$ Generation Software \\
\hline Requirements & Manual and electronic advice forms \\
\hline Information Gathering & $\begin{array}{l}\text { World Wide Web (e.g. Bloombergs), telephone discussions } \\
\text { with broker, and directives from management }\end{array}$ \\
\hline Level of Management & Operational and tactical \\
\hline Transaction Method & Telephone, Telefax, Letter Confirmation \\
\hline Transaction Execution & Electronic prior funds transfer, , SWIFT Global Network \\
\hline Type of Trades & Simple trades, options, futures, and other derivatives \\
\hline Outcome & Limited capacity to manage gains or losses \\
\hline Nature of Risk & $\begin{array}{l}\text { Increasingly sophisticated modeling needed to offset risk and } \\
\text { exposures }\end{array}$ \\
\hline Risk Management & Electronic Spreadsheets \\
\hline \multicolumn{2}{|c|}{ The Future 2006 and beyond } \\
\hline Information System Type & $\begin{array}{l}\text { Electronic and next generation software e.g Agents, Semantic } \\
\text { Web }\end{array}$ \\
\hline Requirements & $\begin{array}{l}\text { Policy driven risk management strategies with scope to } \\
\text { develop highly customized solutions }\end{array}$ \\
\hline Information Gathering & $\begin{array}{l}\text { World Wide Web (e.g. Bloombergs), telephone discussions } \\
\text { with broker, directives from management, proactive software } \\
\text { looking for potential opportunites and matching trades, agent } \\
\text { assisted price discovery and analysis. Simulations and } \\
\text { interactive models }\end{array}$ \\
\hline Level of Management & Operational, Tactical and Strategic \\
\hline Transaction Method & Agent-to-agent and agent mediated \\
\hline Transaction Execution & Electronic prior funds transfer, SWIFT Global Network \\
\hline Type of Trades & $\begin{array}{l}\text { Simple trades, options, futures, and other derivatives trend } \\
\text { towards customized derivatives }\end{array}$ \\
\hline Outcome & Reduced risk, increased opportunity \\
\hline Nature of Risk & $\begin{array}{l}\text { Increasingly sophisticated modeling needed to offset risk and } \\
\text { exposures }\end{array}$ \\
\hline Risk Management & Electronic Spreadsheets \\
\hline
\end{tabular}


the implications of eBusiness for their business. General perceptions included; that eBusiness doesn't involve much change and that existing platforms, marketing approaches and organizational structures were adequate to meet eBusiness challenges.

Table 3: Developments in Treasury IS systems (source: original research)

\begin{tabular}{|c|c|c|c|}
\hline & $\begin{array}{c}\text { Past } \\
\mathbf{1 9 7 6}-\end{array}$ & $\begin{array}{c}\text { Present } \\
\mathbf{2 0 0 6}\end{array}$ & $\begin{array}{c}\text { Future } \\
\mathbf{2 0 0 6}-\end{array}$ \\
\hline $\begin{array}{c}\text { Treasury IS } \\
\text { Technorlying }\end{array}$ & Manual & $\begin{array}{c}\text { Electronic } \\
\text { isolated reactive } \\
\text { systems, e.g. } \\
\text { spreadsheets }\end{array}$ & $\begin{array}{c}\text { Electronic } \\
\text { integrated agent- } \\
\text { oriented, proactive }\end{array}$ \\
\hline $\begin{array}{c}\text { Treasury IS } \\
\text { Type }\end{array}$ & Transaction & Management IS & $\begin{array}{c}\text { Intelligent } \\
\text { Decision Support } \\
\text { Tools and Executive } \\
\text { IS }\end{array}$ \\
\hline $\begin{array}{c}\text { Management } \\
\text { Decision Making } \\
\text { appropriately } \\
\text { supported }\end{array}$ & Operational & Tactical & $\begin{array}{c}\text { Strategic } \\
\text { Nature of Risk } \\
\text { that can be } \\
\text { effectively managed }\end{array}$ \\
\hline
\end{tabular}

Table 4: Developments in IS compared with Treasury Management Systems [3].

\begin{tabular}{|c|c|c|c|}
\hline & $\begin{array}{c}\text { Past } \\
1976 \text { - }\end{array}$ & $\begin{array}{c}\text { Present } \\
2006\end{array}$ & $\begin{array}{l}\text { Future } \\
2006 \text { - }\end{array}$ \\
\hline IS & $\begin{array}{l}\text { Electronic and } \\
\text { largely limited by } \\
\text { Hardware } \\
\text { Capabilities }\end{array}$ & $\begin{array}{l}\text { Electronic and } \\
4^{\text {th }} \text { and } 5^{\text {th }} \\
\text { Generation } \\
\text { Computing Systems }\end{array}$ & $\begin{array}{c}\text { Electronic, } \\
\text { Mobile, } \\
\text { Pervasive, } \\
\text { Ubiquitous, Agile, }\end{array}$ \\
\hline $\begin{array}{c}\text { Treasury } \\
\text { Management } \\
\text { Systems }\end{array}$ & $\begin{array}{l}\text { Manual focus on } \\
\text { transaction } \\
\text { processing }\end{array}$ & $\begin{array}{l}\text { Electronic focus } \\
\text { on transaction } \\
\text { processing }\end{array}$ & $\begin{array}{c}\text { Electronic } \\
\text { focus on strategic } \\
\text { and legal issues }\end{array}$ \\
\hline
\end{tabular}

\section{Treasury Management Systems Today}

Treasury Management Systems have come a long way from the traditional spread sheet systems of yesteryears where the data was collected and entered manually into the software. Besides being prone to human error the system was limited by its capabilities. Although spreadsheets have come a long way since their development in the 1970 s they are still limited in the context of treasury management since they are unable to provide support for non linear analysis of the mathematical models that are now prevalent in the industry. The evolution of Database Management Systems gave 
rise to one point of entry for the data and made the vast amounts of data more manageable. However the treasurers still relied heavily on the use of spread sheets for the analysis to gauge hedge positions and risk exposures.

The changing philosophy of risk management and the role of treasury in the organization has placed a greater emphasis on consolidated risk management. Consolidated risk management - sometimes also called integrated or enterprise-wide risk management - generally refers to a coordinated process for the measurement and management of risk on a firm-wide basis. The conventional wisdom dictates that consolidated risk management will help companies assess risks and returns of different business lines and thus allow them to make more informed decisions about where to invest scarce resources to maximize profit [9].

Consolidated risk management can be clearly understood if we make a distinction between risk measurement and risk management. Risk measurement entails the quantification of risk exposures such as Value-at-risk, earnings-at-risk, stress scenario analyses, duration gaps, etc. depending upon the type of risk being measured and the degree of sophistication of the estimates. In contrast, risk management refers to the overall process that a company follows to define a business strategy, to identify the risks to which it is exposed, to quantify the risks and to understand and control the nature of the risks it faces. Risk management is a series of business decisions, accompanied by a set of checks and balances, risk limits, risk reporting, review and oversight by senior management and the board. Thus consolidated risk management involves not only an attempt to quantify risk across a diversified business but also a much broader process of business decision making and support to management in order to make informed decisions about the extent of risk taken both by individuals and the business as a whole [9].

As a result the present day treasury management systems offer some key features:

- Multi-currency capability for viewing, printing and exporting data.

- Improved search interface to narrow selected criteria quickly and efficiently.

- Standardised format for data collection across the business network.

- Local account information including subsidiary account-profiles, local policy summaries, etc.

- Reporting capabilities.

These systems in general provide ease of data management and manipulation, reduced costs through minimization of coverage overlap, increased efficiency from the automation of historically paper-based processes, reduced exposures, increased productivity, access to real-time account information so decisions can be based on most up-to-date information and gives a consolidated "big-picture" view of the global coverage.

\section{Next Generation Treasury Management Systems}

Innovative companies have realised that they can not wait for the future to happen and they have to actively position themselves accurately in the future to manage the risk which arises from such a volatile environment. For example, if a company has to predict with a high accuracy what it expects its sales to be in the future, what would be the cost of the fuel in the future and also what the exchange rates would be, a next generation system would require:

1. Learning: The ability to learn directly from decisions or tasks they have to perform. The IS should be able to derive a model of business practice purely by 
analyzing the data. Typically such knowledge is held by operational personnel with many years of experience. Genetic Algorithms and Neural Networks have the capability to perform such a task. This is in strict contrast to the earlier systems where the knowledge required to perform these tasks had to be explicitly specified by human intervention. This learning technique also overcomes the limitation set due to different opinions of different experts and as such is more consistent.

2. Adaptation: Businesses and business processes are constantly changing due to changes in the macro-economy, competitive pressures, government regulations and as such Intelligent Systems providing decision support should be able to adapt. Such systems should be able to monitor their own performance and revise their knowledge consistently with the changing environment. For example interest rates can fluctuate over a very short period of time. The Intelligent system should be able to learn from the market and be able to adapt to such changes before making any recommendations.

3. Flexibility: Experienced personnel can make decisions even when the available information is unclear, imprecise or incomplete - a characteristic often seen in financial markets. Most traditional computer programs are inefficient under such constraints. Any Intelligent system should then have the flexibility to make recommendations and support business decisions in such an environment.

4. Transparency: Intelligent systems that automate many different decision making tasks should be transparent in their decision making process so that they could easily be understood by humans. This has become even more important recently with the legal requirements imposed by legislation such as IAS 39 which holds the board accountable for the decisions of the company specifically for the use of options and other derivatives for hedging. Moreover this transparency is required to enable the Intelligent system to adapt to future changes. This also allows easy interaction with the experts if models have to be changed.

5. Proactive: The Intelligent systems should offer the possibility of discovering new business processes or relationships that were previously unknown. This could potentially give rise to new trading and hedging strategies. Traditional systems which are conventionally operated by humans provide no such opportunity $[6,12]$.

\section{Issues for IS Research}

The necessity for a multidisciplinary research focus is apparent in a specialist business function like treasury. Finance and treasury have a rich research tradition but not usually in adoption, diffusion, implementation and evaluation of enabling technologies for TM functions. These represent an IS focus. The intersection of the disciplines does reveal some research interest. Treasury risk management is concerned with the need to assess the impact of emerging technologies, models and model risk.

The major lesson for IS research is a reminder that technology cannot be analyzed in a vacuum, and that business and environment factors as well as inhibitors and drivers of technology adoption play a crucial role [6] This caution is particularly pertinent where ICT is developing so rapidly. There is a temptation to focus on the changing technology and to treat it as something new whereas the IS focus is on applications of the technology and how these may be more successfully accomplished. 
Researchers reviewing Tables 2, 3 and 4 and the requirements for TM systems in sections 6 and 7 will note a myriad of research implications. A better understanding of technology adoption is important especially in light of the fact that resistance may be anticipated [10] particularly with the introduction of disruptive technologies [3].

\section{Issues for Treasury Management Practice}

Confronted by volatile global markets creating severe business challenges and dynamically developing technological capabilities that may be able to address their challenges, business management as a whole and treasury management in particular needs to establish mechanisms to monitor, evaluate and successfully innovate to realize the potential benefits from technology. A key prerequisite in acquiring this innovative capability is a willingness to change and to learn from these experiences.

Surveys [10] have revealed a puzzling resistance in firms to embrace necessary change, to explore better, cheaper and faster ways of doing business. Perhaps this is a corporate manifestation of Darwin's survival of the fittest! Such developments need not be technology-based. Consolidation and integration of treasury management at organisational and inter-organizational levels are an option. Smart companies are relinquishing ownership of non-core specialist value chain activities [13, p7] where business benefits are available. Ultimately, the technology-based opportunities presented in Tables 2,3 and 4 will need to be compared with the possible requirements listed in sections 6 and 7 . Innovative management will be thinking about further opportunities to improve current practice: "Technology offers possibilities for business we hadn't considered in the past." [14]

\section{Discussion}

This paper seeks to contribute to the discipline of Information Systems by illustrating the continuing evolution of IS in a single, core business function. Historical developments in IS and the major global treasury activity, foreign exchange trading, have been examined to establish the context. Possible future developments in IS applications have been explored not as wildly speculative guesses but based on the capabilities of emerging technologies to address current treasury problems as described by reviews of the literature, results arising from a seven year research project into the impact of ICT on financial services and the development of a next generation agentbased treasury management system prototype..

Sustainable research issues and themes in IS are identified and activities to assist Treasury Management succeed in an increasingly complex, global market are presented. Next generation IS applications are considered for how they might address Treasury Management challenges in the future.

As with many business functions, treasury has experienced small, incremental changes over the last 30 years. Until quite recently. Substantial changes in current practice are sweeping across corporations and treasury departments will not be excluded. So what might the next 10 years hold in store? More upheaval! 'The disruption to a lot of traditional businesses has only just begun [6]. 


\section{References}

1. M.E. Porter. Strategy and the Internet, Harvard Business Review; March, Vol. 79 Issue 3, 62-78 (2001)

2. S. Elliot, and M-A. Williams. Intelligent Agent and Semantic Web enabled Innovation in the Wholesale Financial Services Industry, Proceedings of Collector Conference (Toulouse, April 2002).

3. S. Elliot, M-A. Williams, and N. Bjørn-Andersen. Strategic Management of Technology-enabled Disruptive Innovation: Next Generation Web, in the Proceedings of the International Conference on Intelligent Agents, Web Technology and Internet Commerce, IEEE Computer Society Press, (2005).

4. A. Karol and M-A. Williams. Understanding Human Strategies for Belief Revision: An Empirical Study, in the Proceedings of the Tenth conference on Theoretical Aspects of Rationality and Knowledge (TARK X) Halpern, J. and Van der Meyden (eds), (2005).

5. V. Zwass. Electronic Commerce and Organizational Innovation: Aspects and Opportunities, International Journal of Electronic Commerce, Volume 7, Number 3, Spring, pp. 7-37 (2003).

6. M-A. Williams and S. Elliot. An Evaluation of Intelligent Agent-based Innovation in the Wholesale Financial Services Industry, Proceedings of Second IFIP WG 8.4 Working Conference, Kluwer, 91 - 106, (2003).

7. S. Haag, M. Cummings, and D.J. McCubbrey. Management Information Systems for the Information Age, $5^{\text {th }}$ edition, McGraw Hill Publishers, (2005).

8. H.A. Simon. Rational Decision Making in Business Organizations, American Economic Review, American Economic Association, vol. 69(4), pages 493-513 (1979).

9. C. Cumming and B.J. Hirtle. The Challenges of Risk Management in Diversified Financial Companies Federal Reserve Bank of New York Economic Policy Review / (March 2001).

10. Arthur Andersen. Thriving in the New Economy: Perception vs. reality, Financial Services Report, Issue no. 2 | January, Executive Summary (2000)

11. C.S. Amaravadi The world and business computing in 2051 , Journal of Strategic Information Systems 12 (2003) 373-386

12. M-A. Williams and S. Elliot. Corporate Control of Rogue Traders: An Evaluation of Intelligent Agents for Improved eBusiness Treasury Risk Management in Elliot S., Andersen K.V. and Trauth E. (eds) Multi-Disciplinary solutions to Industry \& Governments' E-Business Challenges (Trauner, Austria, 2004).

13. A. Barua and A. Whinston. Measuring the Internet Economy, CISCO Systems and the University of Texas. June 6, www.internetindicators.com (2000).

14. G. Cox. Business computing 2001-the state of the art, Journal of Strategic IS 12 (2003) 285-294 